\title{
الذكاء الوجداني وعلاقته بالأمن النفسي لدى عينة من طلاب الجامعة بليبيا
}

\author{
! \\ الباحثة/ طرفة ضو فرج امعيقل
}

$$
\begin{aligned}
& \text { - غ غ إشراف }
\end{aligned}
$$

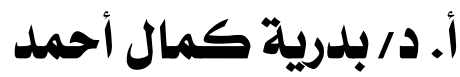

$$
\begin{aligned}
& \text { أستاذ علم النفس } \\
& \text { كليتّالآداب- جامعت المنصورة } \\
& \text { المجلت العلميت لكليتترياض الأطفالـ جامعت المنصورة } \\
& \text { المجلد الثالث ـالعدد الثالث }
\end{aligned}
$$

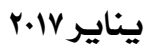


الذكائ الوجداني وعلاقته بالأمن النفسي للدى عينة

من طلاب الجامعة بليبيا

أر طرفتشضو فرجامعيقل **

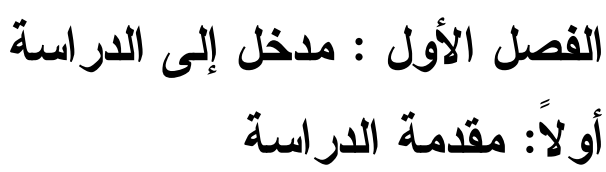

يُعّد موضوع الذكاء الوجدانى من الموضوعات الأساسية التى اهــتـم بهـــا

علماء النفس منذ بداية القرن العشرين، حيث حظي هذا الموضوع في العقـدين الأخرين من القرن الماضى باهتمام الكثير من الباحثين في علم النفس حيث بات

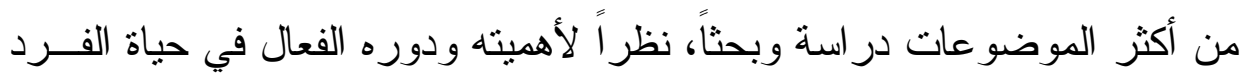
وصلته الوثنقة بتفكيره وذكائه، و إسهامة الو اضح في نجاحه وقدرته على التكيف في المو اقف الحياتية التى يتفاعل فيها مع أفر اد مجتمعه.

هذا وللاكاء الوجداني دور كبير في نجاح الفرد في تحقيق أهدافه بـصفة

عامة، فعندما يكون لاى الفرد قلب مسئول عن الجانب العاطفي، و عقل مـسئول عن التفكير و الإدر الك والتذكر و الانتباه، وبدن معافى، منل هذا الثخص يستطيع

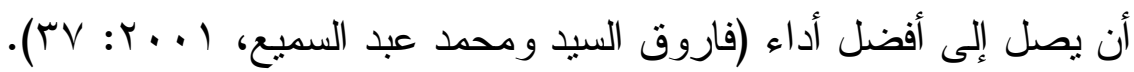
ويُعد إثباع الحاجه إلى الأمن و الطمأنينة ضروري للنمو النفسي الـسوي للإنسان و التمتع بالصحة النفسية السوية في جميع مر احل الحياة. وتــشير نتــائج الدر اسات إلى أن الأشخاص الآمنين منفائلون، ومتو افقون ومعظمهم ناجحون في هري أعمالهم وسعداء في حياتهم (علاء عبد الباقى، ؛ ( • ب: • ؟). 


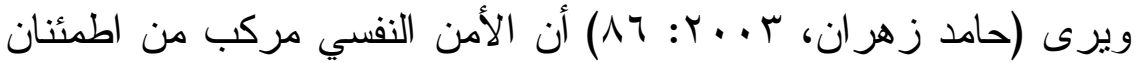
الذات و الثقة في الذات و التأكد من الاتنماء إلى جماعة آهنة. ثانياً: مشكلة الار اسة في بدأ مفهوم الذكاء الوجداني يتبو أ مكانة خاصة في ميدان علم النفس، حيث

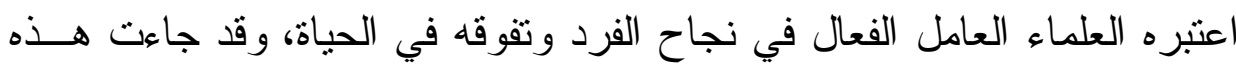

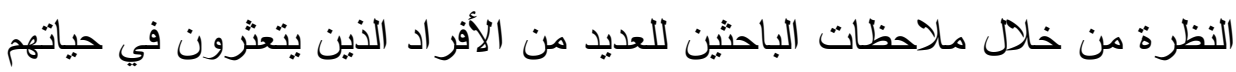

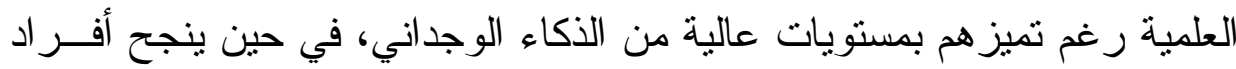

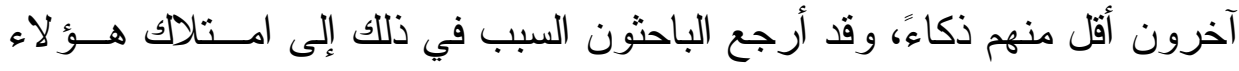

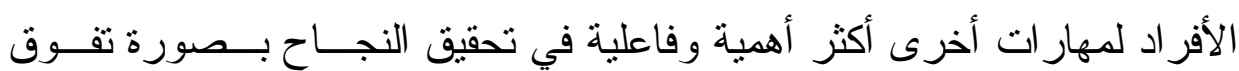

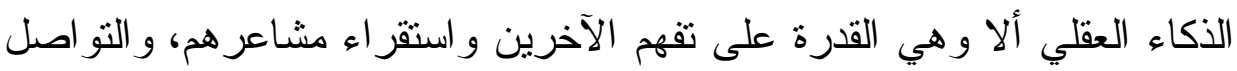

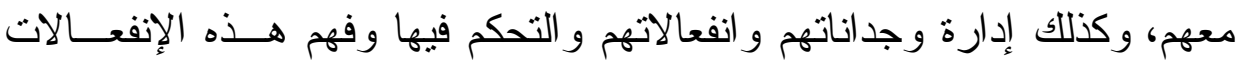

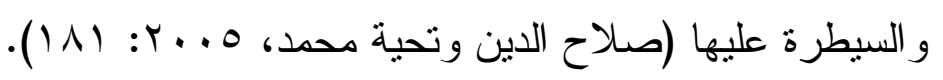
ويُعدُ الأمن النفسي من أهم العناصر في تكوين الثخصية، و عامل أساسي

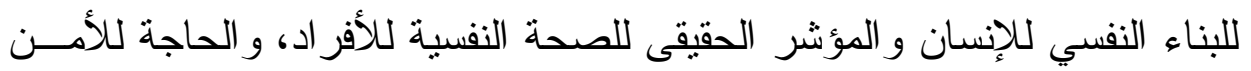

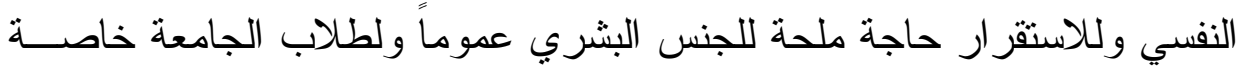

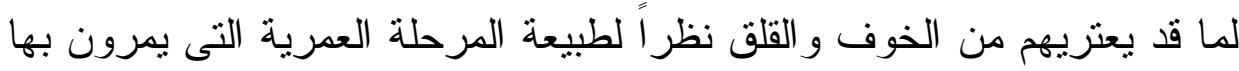

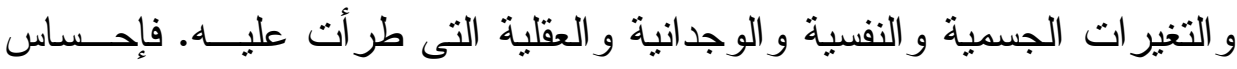

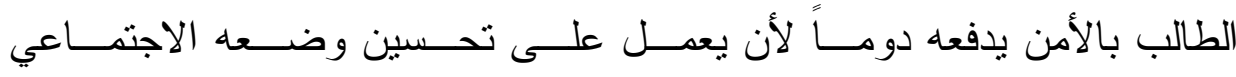

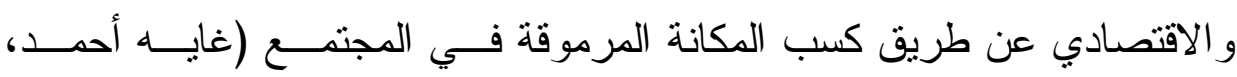
. $(r: r \cdot r$

وترى الباحثة من خلال استقر اء الدر اسات السابقة التى تتاولــت العلاقـــة

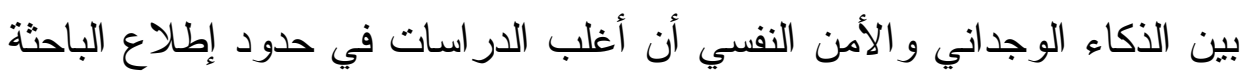


- أنثارت إلى وجود علاقة بين الذكاء الوجداني و الأمن النفسي متل دراسة كـلـل

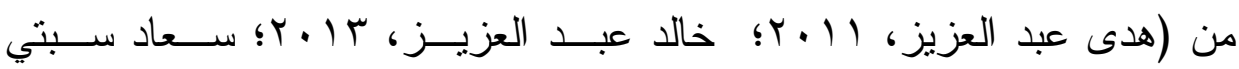

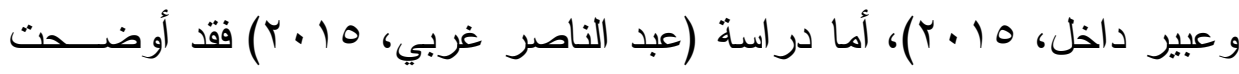

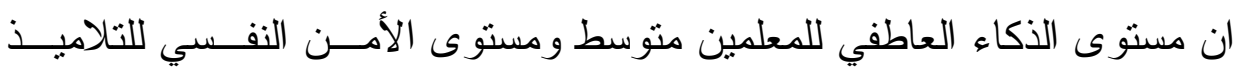
منوسط.

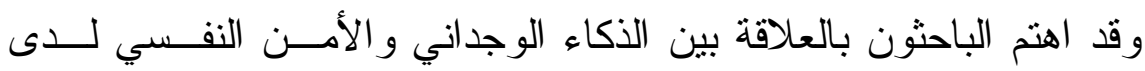

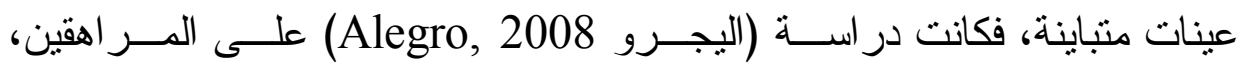

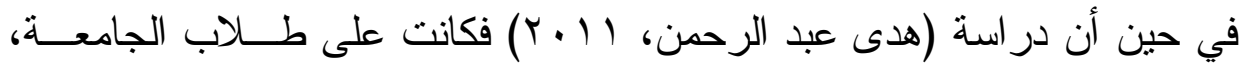

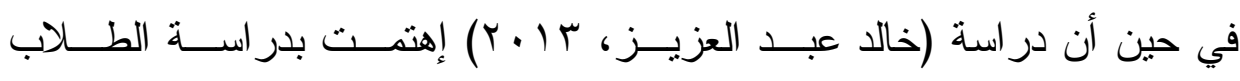

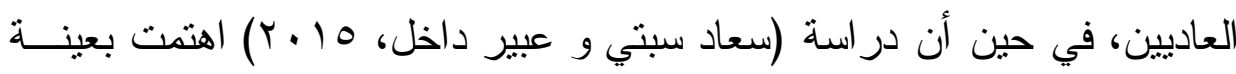

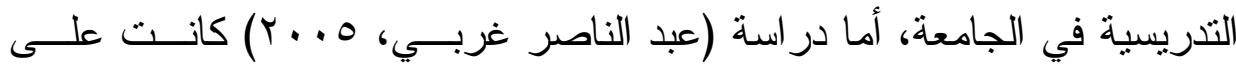

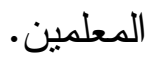

وفي ضوء ما سبق يمكن تحديد مشكلة الدراسة في محاولـــة الإجابــة

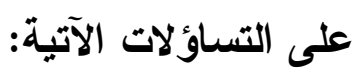

1- هل توجد علاقة بين الذكاء الوجداني و الأمن النفسي لدى عينة من طلاب

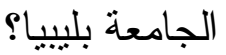

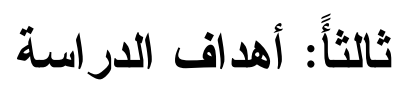
يمكن تحديد أهداف الاراسة في التعرف على:

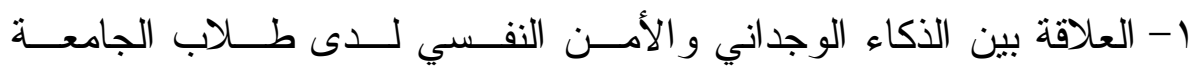
بليبيا. 


\section{رابعاً: أهمية الدراسة}

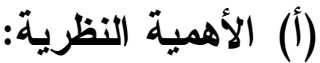

1- يُعدُ مفهوم الذكاء الوجداني من المفاهيم الحديثة نـسبياً فــي الدراســات

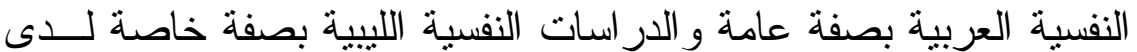

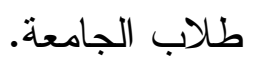

r- الأهمية المتز ايدة لموضوعات الذكاء الوجداني و الأمن النفسي لدى طلاب

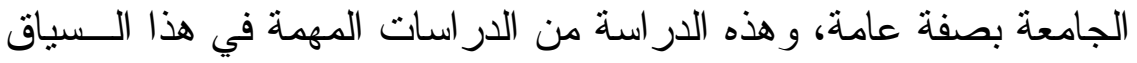

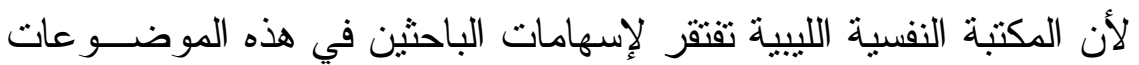

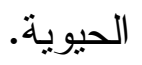

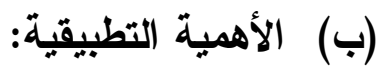

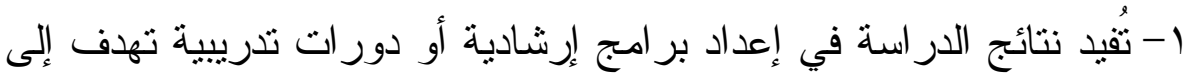

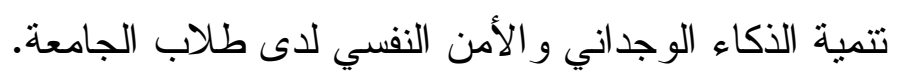

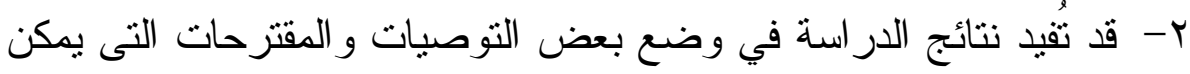

$$
\begin{aligned}
& \text { الإستفادة منها في تلبية احتياجات طلاب الجامعة. } \\
& \text { خامساً: مصطلحات الدر اسة }
\end{aligned}
$$

\section{1 الأكاء الوجداني Emotional Intelligence}

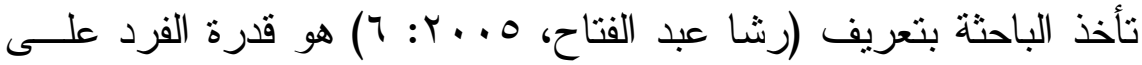

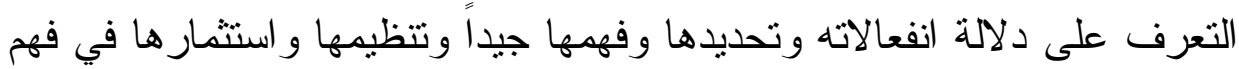

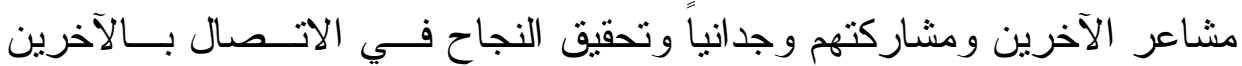

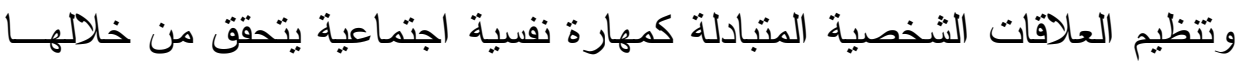
الصحة النفسية و التو افق مع النفس و الآخرين و العالم المحيط. 


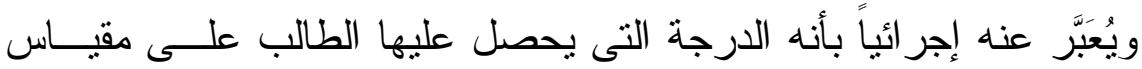

$$
\text { الأكاء الوجداني. }
$$

\section{Psychological Safety الأمن النفسي}

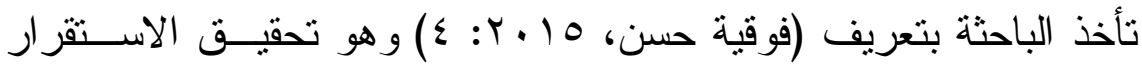

للدى الفرد من خلال شعوره بالعيش في بيئة يتو افر فيها الأمان و الحرية و الهدوء

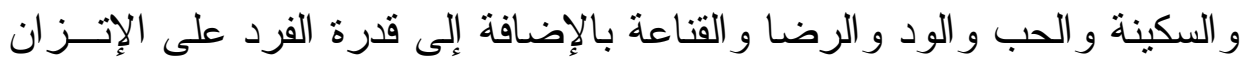

النفسي و التو ازن بين القوى الخارجية ومصالحة الثخصية.

ويُعَبَّر عنه إجر ائيًاً بأنه الدرجة التى يحصل عليها الطالب علــى مقيــاس

الأمن النفسي المستخدم في الدراسة.

سادساً: حدود الار اسة النسة

1- الحدود الموضوعية: الذكاء الوجداني و الأمن النفسي.

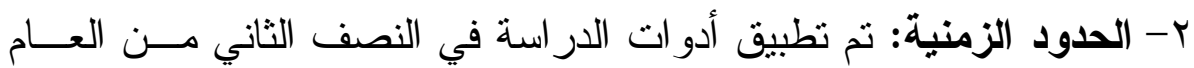

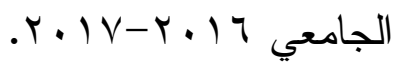

r- الحدود المكانية: نم التطبيق على بعض كليات جامعة الزيتونـــة " كليــة

الآداب، و الحقوق، و العلوم، و الاقتصاد" بنى وليد بليبيا.

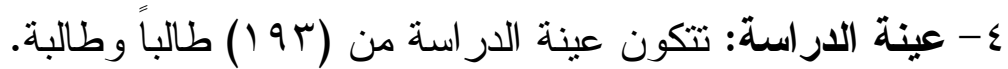

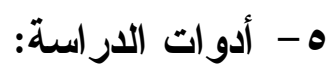

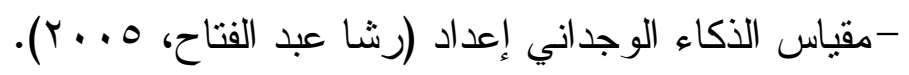

- مقياس الأمن النفسي إعداد (فوقيه حسن، 0 المباء ب).

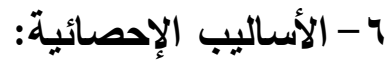

- اختبار ا "ت" t. test لحساب دلالة الفروق بين المتوسطات. 


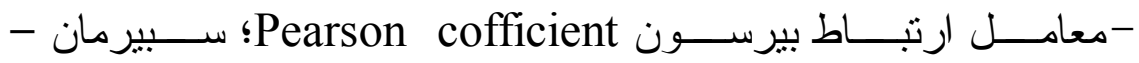

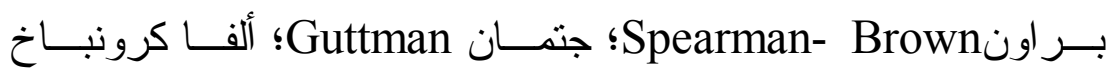

.Alpha cronbach

- هذا، وتم استخدام الحزمة الإحصائية للعلوم الاجتماعية Spss لإجـــراء المعاملات الإحصائية المستخدمة في الدر اسة.

$$
\text { سابعاً: نتائج الدراسة }
$$

- توجد علاقة إحصائية دالة بين الذكاء الوجداني و الأمن النفسي لــدى عينـــة

$$
\text { الدر اسة. }
$$

\section{جدول (1)}

يوضح قيم معامل الارتباط بين درجات المفحوصين على مقياس

\begin{tabular}{|c|c|}
\hline الأمن النفسي & أبعاد الذكاء الوجداني \\
\hline$F * *, Y Y$ & الوعى الذاتي \\
\hline$* * *, \Gamma \wedge$ & تنظيم الوجدان \\
\hline$* * *, r \mu$ & الدافعية الثخصية \\
\hline$* *, Y \Sigma$ & المشاركة الوجدانية \\
\hline$* *, r$. & معالجة العلاقات \\
\hline$* * \cdot, \varepsilon 7$ & ة الكلية للأكاء الوجدا \\
\hline
\end{tabular}

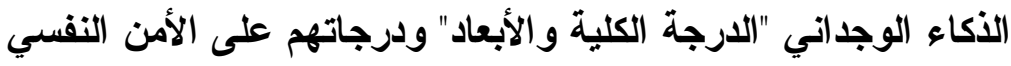

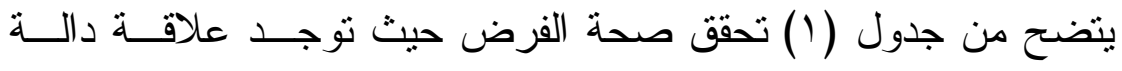

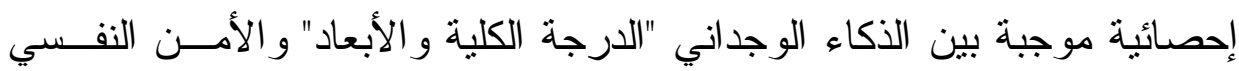

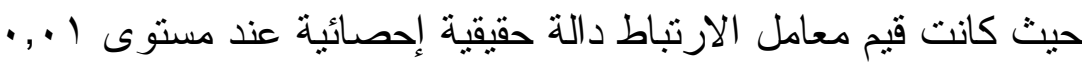




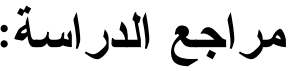

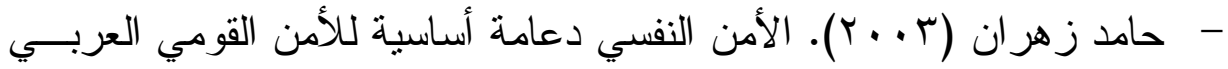

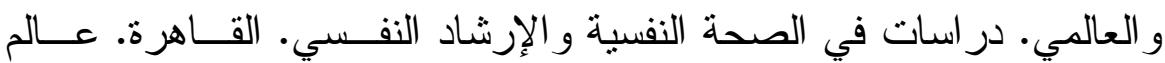

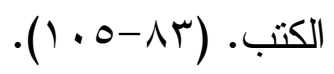

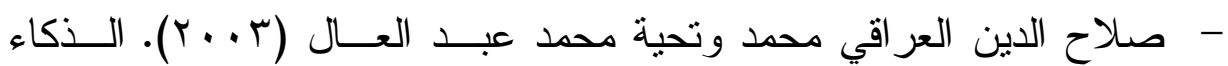
الوجدانى وعلاقته بالسلوك القيادي للمعلم. المؤتمر السنوى الثـاني عـشـر .

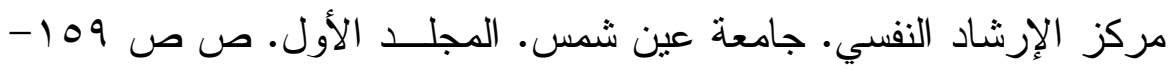
.rY)

- غاية أحمد الثيخ قاسم (T . . ץ). الأمن النفسي لاى طلاب المرحلة الثانوية

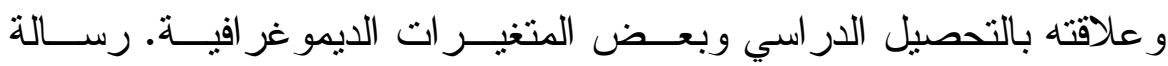
ماجستير • كلية الدر اسات العليا. جامعة الخرطوم.

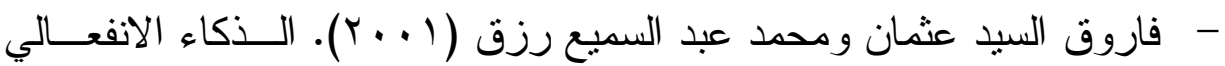

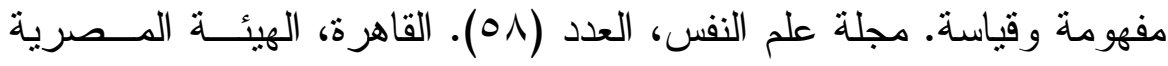

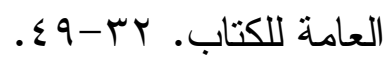

